JOURNAL OF ENGINEERING SCIENCES

ЖУРНАЛ ІНЖЕНЕРНИХ НАУК

ЖУРНАЛ ИНЖЕНЕРНЫХ НАУК

Web site: http://jes.sumdu.edu.ua

\title{
Cleaning and disposal of gas emissions from the production of calcinated soda ash
}

Moiseev V., Manoilo E., Hrubnik A., Vasyliev M., Davydov D.

National Technical University “Kharkiv Polytechnic Institute”, 2 Kyrpychova St., 61002, Kharkiv, Ukraine

Article info:

Paper received:

The final version of the paper received:

Paper accepted online:
October 30, 2017

November 25, 2017

November 27, 2017
*Corresponding Author's Address:

gr_alia@mail.ru

\begin{abstract}
The article is devoted to the issues of reducing the negative impact on the environment of the production of soda ash, which is achieved by reducing the formation of gas and dust emissions, as well as their deeper cleaning. The problem of cleaning gas emissions from the production of soda ash is solved by using hollow vortex devices, their comparison with operating apparatus is given. The advantages of multi-stage vortex-type apparatuses for cleaning large volumes of industrial gas emissions are noted. The article states that the task of cleaning of industrial gas emissions is significantly complicated by their large volumes, which makes it difficult to use traditional treatment equipment. Most of the devices currently used to clean gases from gaseous, liquid and solid impurities are characterized by low throughput due to small maximum permissible gas velocities in the apparatus.

The necessity of using multistage vortex devices for cleaning gas emissions from ammonia and soda dust is substantiated. The advantages of the apparatus of this group are noted - low hydraulic resistance, high efficiency and low energy and metal capacity. The comparison of vortex devices with other active gas cleaning devices according to fractional efficiency is given. The scheme of purification of gas emissions from soda dust, with its further utilization, is proposed. The efficiency of submicron particle deposition in a vortex apparatus with intensive phase interaction may exceed $95 \%$.
\end{abstract}

Keywords: industrial gas emissions, cleaning, mass transfer, vortex apparatus, investigation of cleaning processes, ammonia, soda ash dust.

\section{Introduction}

Waste-free and low-waste technologies represent one of the current trends in the development of industrial production and are associated with the need to eliminate the harmful effects of industrial waste on the environment. Wasteless production involves the development of technological processes that ensure the integrated processing of raw materials. This makes it possible to effectively use natural resources, process waste into commercial products, and also reduce the amount of waste and their negative impact on ecological systems.

Wasteless and low-waste technologies are used in all industries, developing in the direction of developing and implementing fundamentally new technological processes that reduce the amount of waste; development and introduction of methods and equipment for waste processing into commercial products; creation of drainless water recycling systems in which water purification is carried out and the efficiency of gas phase cleaning is improved.
To reduce the level of environmental pollution, save raw materials and energy, re-use of material resources, namely their recycling, is of great importance.

A set of measures to minimize the amount of hazardous waste and reduce their impact on the environment include:

- development of drainless process systems and water cycle systems based on wastewater treatment;

- the development of systems for processing waste products into secondary material resources;

- creation and release of new types of products, taking into consideration the requirements for its re-use;

- the creation of fundamentally new production processes that make it possible to exclude or reduce the technological stages at which waste is generated.

The initial stage of these complex measures aimed at creating in the future non-waste technologies is the introduction of circulating, down to completely closed technological systems.

Turnover water supply is a technical system that provides for the reuse of waste water in the production (after 
treatment) with very limited discharge (up to $3 \%$ ) into water bodies.

A closed cycle of water use is a system of industrial water supply and sanitation, in which the repeated use of water in the same production process is carried out without the discharge of sewage and other water into natural water bodies.

Progress of new technological schemes of water supply is determined by the extent to which the water consumption, the amount of sewage and their contamination decreased compared to earlier ones. The presence of a large amount of sewage at an industrial facility is considered an objective indicator of the imperfection of the technological schemes used.

The development of non-waste and anhydrous technological processes is the most rational way of protecting the environment from pollution, which allows to significantly reduce anthropogenic load.

The complete transfer of industrial and agricultural production to wasteless and waterless technologies is associated with complex organizational, technical and financial problems.

The concept of non-waste production provides for the need to include the consumption sphere in the cycle of using raw materials. Thus, products after physical or moral deterioration should be returned to the production sphere, methods of neutralization, utilization, processing or disposal of waste should be improved. It should be noted that non-waste production involves the cooperation of industries with a large amount of waste (the production of phosphate fertilizers, thermal power plants, metallurgical, mining and concentrating industries) with the production-consumer of this waste.

By disposing of sulfur dioxide contained in the exhaust gases, heat and power engineering and metallurgy, it is possible to obtain a large amount of sulfuric acid by increasing the production of this valuable product of chemistry. Sulfuric acid, used in agriculture to make neutralizing composition, can find an unlimited market for soils of soda salinity.

Technological measures to protect atmospheric air from pollution also involve the creation of waste-free and low-waste technologies and technological means for the integrated use of raw materials, the disposal of industrial waste, the organization of technological industrial complexes with a closed system of material balance of substances, including production waste.

The most effective measure of atmospheric air protection is the construction of enterprises operating on the principle of non-waste technologies, with closed technological processes, with the elimination of emissions of tailings and tail gases into the atmosphere. The introduction of even partial recirculation of gases, replacement of coal and fuel oil with natural gas give a good ecological and economic effect. The change in technology follows the path of reducing the amount of emissions and reducing the costs of gas cleaning per unit of output.
One of the promising directions for the development of wasteless and low-waste technologies is the introduction of gas cleaning with the use of a catalytic afterburning system, which is used for cleaning solvent vapors of paints containing organic and non-oxidized substances: esters, hydrocarbons, toluene, xylene.

Considerable practical importance for gas purification is also provided by preventive measures, consisting in improving fuel combustion conditions, improving the design of filters and other gas, dust-collecting equipment, and sealing technological lines.

The main criteria of technologies for waste processing are environmental safety and economic efficiency, expressed in the cost of processing one ton of waste. Technologies for recycling production wastes can be classified as follows [1]:

- thermal technologies;

- physicochemical technologies;

- biotechnology.

The development of waste-free and water-free processes - the most efficient way to protect the environment from pollution, which drastically reduce the human pressure on the environment.

Effectively solve the problems of environmental protection and rational use of natural resources is possible only by improving the methods of neutralization, utilization, processing or disposal of waste.

\section{Analysis of recent research}

The chemical industry complex lays the foundation for long-term and stable development of the country and has a significant impact on structural changes in the economy. The branch of chemistry and petrochemistry is characterized by a wide range of types of products that are used in virtually all industries, the national economy and in everyday life. Analysis of the structure of consumption of soda ash showed that about $49 \%$ of soda ash is used for the production of glass, about a quarter for chemicals, $13 \%$ for soap and detergents, $11 \%$ for purposes such as cellulose and paper, refining metals and oil, tanning skin and water purification, and the rest goes on sale. On Fig. 1 the structure of consumption of soda ash in Ukraine is presented.

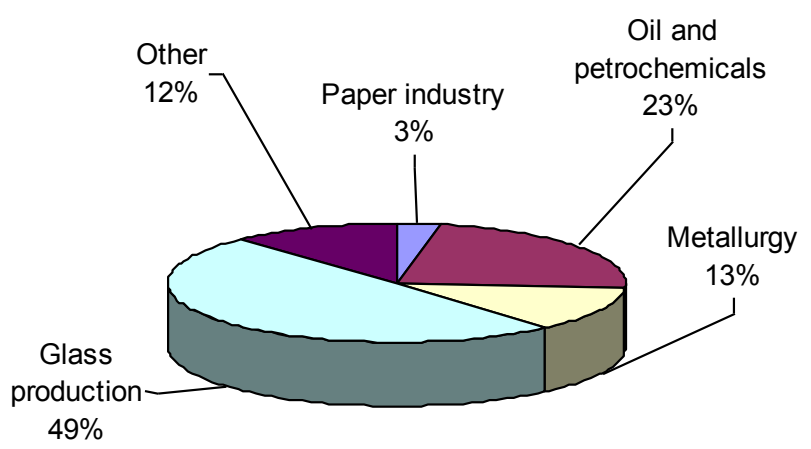

Figure 1 - The structure of consumption of soda ash in Ukraine 
The growth in industrial production caused an increase in emissions to the environment, and the development of a large number of new technological processes led to an increase in the number of toxic substances entering the atmosphere. The total amount of harmful substances in emissions is small, but due to the location of soda plants in regions with chemical plants and the proximity of residential areas, concentrations in the residential area and at the boundaries of sanitary zones of plants are higher than the maximum allowable concentrations.

The reasons for this situation are manifold, but the main one is that the cleaning of industrial gas emissions has not only been neglected for a long time, and the attitude to the issue has implied the ability of the environment to unlimited self-cleaning.

\section{Identification of previously unsolved problems}

Improvement of soda production until recent years has been aimed at improving technology and upgrading the equipment of the main production cycle. The creation of equipment for the protection of the environment was not given much attention. Gases and liquids were cleared only of ammonia to the limits substantiated economically, and not sanitary norms.

Only recently, systems for cleaning emissions and utilizing the heat of secondary sources have been developed and implemented. This, in turn, requires the development of scientific principles for the design of devices for cleaning gas emissions of soda production. In addition, the introduction of traditional systems and installations for cleaning industrial emissions require large capital and operating costs.

From the technological cycle of soda production are output: gas streams, liquid industrial effluents and solid sludge. When 1 ton of soda ash is produced, the following substances are removed from the technological cycle [2]:

\section{Components of gaseous streams:}

- ammonia - $1.5 \mathrm{~kg}$;

- carbon monoxide $-27 \mathrm{~kg}$;

- oxides of nitrogen $-0.8 \mathrm{~kg}$;

- sulfur dioxide $-5.6 \mathrm{~kg}$;

- dust $-0,4 \mathrm{~kg}$.

2. Liquid industrial effluent:

- water from water rotation $-5 \mathrm{~m}^{3}$;

- weakly mineralized runoff $-2 \mathrm{~m}^{3}$;

- flushing water with calcium chloride and sodium chloride $-2.3 \mathrm{~m}^{3}$;

- clarified distillation liquid $-9.8-10 \mathrm{~m}^{3}$.

\section{Solid slimes:}

- brine cleaning mud (containing calcium carbonate, magnesium hydroxide, sodium chloride, calcium sulfate and water) $-25 \mathrm{~kg}$;
- small waste of quenching (containing calcium oxide, calcium carbonate and others) $-81 \mathrm{~kg}$;

- distillery slurry (containing calcium carbonate, magnesium carbonate, calcium oxide, sodium chloride, calcium chloride, calcium sulfate and water) $-250 \mathrm{~kg}$.

Annually, soda enterprises withdraw about millions $\mathrm{m}^{3}$ of liquid industrial effluents and gaseous substances, millions of tons of solid waste and dust from the technological cycle. [2]. And in the future it is expected to continue rapid growth in the world scale of industrial production of soda ash, which will inevitably lead to an increase in the amount of waste generated [3].

In comparison with other chemical and petrochemical enterprises soda plants discharge large amounts of harmful emissions into the atmosphere, mainly not related to particularly toxic (dust soda, carbon dioxide, ammonia). Carbon monoxide and a small amount of hydrogen sulphide are also present in the emissions. The emissions from the boiler unit of the soda plant usually contain oxides of nitrogen and sulfur.

\section{Research}

The task of cleaning industrial gas emissions is significantly complicated by the fact that their volumes are dozens, and sometimes hundreds, thousands of $\mathrm{m}^{3} / \mathrm{h}$, which makes it difficult to use traditional cleaning equipment. Most of the devices currently used to purify gases from gaseous, liquid and solid impurities are characterized by low capacity, due to the small maximum allowable gas velocities in the apparatus. This is the reason that highperformance devices have large overall dimensions (for example, the diameter of absorption columns can reach 10-12 m), and the costs of their manufacture, installation and transportation are prohibitive.

The concentration of ammonia in the gas discharge is within the range of $0.1-0.2 \mathrm{~g} / \mathrm{m}^{3}$, and the maximum allowable concentration is $50 \mathrm{mg} / \mathrm{m}^{3}$. The main source of gas emissions of ammonia is the gases after the process of carbonization of the ammoniated brine. At the same time, at the factories there are 4 to 13 second column gas washers.

The traditional bubble gunner of second column gas washer consists of eight elements, bottom and lid [2]. The main mass-exchange element of the apparatus is a bubble-pin device, which is installed inside the contact plate. On each plate there are 17 bubble devices and one nozzle for flooding the liquid through a water jacket on an understated plate. In total, in the bubble gunner of second column gas washer in practice, 8 working plates with bubbling devices are used.

Multi-stage vortex devices are perspective equipment for cleaning large volumes of industrial gas emissions, including ammonia $[1,4]$.

A comparative analysis of the parameters of the operation of devices for gas cleaning testifies to the use of hollow vortex devices with low hydraulic resistance, fairly low energy and metal capacity. 
This makes it very promising to use for cleaning large volumes of gas emissions from vortex-type devices. The use of centrifugal separation in vortex devices removes the restriction on the maximum permissible gas velocity and makes it possible to carry out the processes at medium-velocity gas velocities reaching $20-40 \mathrm{~m} / \mathrm{s}$. The high throughput of vortex devices in the gas phase causes their small overall dimensions. In addition, the advantages of these devices include low metal consumption, relatively low specific energy costs, stability of operation in a wide range of loads in liquid and gas, and ease of manufacture.

Despite the fact that the principles of designing vortextype devices have been developed quite a long time $[4,5]$, their widespread use in industry is hampered by the lack of reliable and valid methods for calculating the efficiency of gas purification processes taking place in them.

Multistage vortex devices are a heat and mass exchange column with contact vortex stages. The contact stage of multi-stage devices is executed in the form of a single vortex stage inside which counter-current motion of phases is realized. In general, in the apparatus phases move the in countercurrent mode.

Features of the technology for cleaning gas emissions from ammonia, as well as the operating principle and design of a multi-stage vortex device are described in detail in the following works $[6,7]$.

A feature of the vortex apparatus is the presence in the working space of a highly developed surface of mass exchange, which includes a drop, film, and foam interface [6]. High relative phase velocities and constant renewal of the phase interface ensure high efficiency of the devices of this design. The coefficient of heat and mass transfer of the apparatus is an order of magnitude higher than in known industrial apparatuses used for the same purposes. This allows you to get the desired result with minimal overall dimensions and metal capacity.

Also, among the most important problems of soda production, the process of which is related to storage, processing, packaging, etc., first of all, pollution of air, industrial premises and territories with soda dust. Such technological processes, as loading, unloading, overfilling, sorting are accompanied by the release of dust. Technology dust is very diverse in chemical composition, size, shape and density of particles. The density of the particles of soda ash varies, generally, from 1000 to $3000 \mathrm{~kg} / \mathrm{m}^{3}$. It contains particles of $3-50 \mu \mathrm{m}$ in size. The formation of fine soda dust is facilitated by the processes of its mechanical processing, as well as various loading and unloading operations, transportation and storage [8].

To clean the gas of large dust, a washer is usually used, which is a chordal apparatus that is watered. To clean the gas of fine dust it is sent to an electrostatic precipitator, a foam washer or a Venturi scrubber [8].

According to the current schemes for cleaning gases from a solid dispersed phase, there are difficulties associated with cleaning the precipitation electrodes during the operation of the electrostatic precipitator from the settled dust. The main drawbacks of scrubbers when capturing solid dust particles are a large flow of irrigating liquid, a short residence time of phases in the contact zone and a high hydraulic resistance [8]. In addition, existing conventional dust-collecting equipment does not effectively capture particles smaller than $10 \mu \mathrm{m}$, and they are largely carried away with the gas stream. These factors necessitate the transition of gas purification systems from the substantial amount of a solid polydispersed phase contained in it to a fundamentally new technology.

Comparative dependence of the capture efficiency on the fractional composition of solid particles and aerosols in the gas stream for different types of equipment is given in Table 1 .

To intensify the trapping of dust, it is necessary to use an intensive mode of interaction of phases with a high turbulence of the streams. Fine dust particles have low inertia, so the cleaning process is possible only in devices with an intensive hydrodynamic mode of operation, for example, such as hollow vortex devices.

In a vortex dust collector, as in a cyclone, dust separation is based on the use of centrifugal forces. In vortex dust collectors, a very high purification efficiency is achieved - 99-99.5\% and higher. The device can be used for cleaning gases with a temperature up to $700{ }^{\circ} \mathrm{C}$.

Table 1 - Efficiency of dust trapping by various designs of gas cleaning equipment

\begin{tabular}{|c|c|c|c|c|c|c|}
\hline \multirow[b]{2}{*}{$\begin{array}{c}\text { Type of } \\
\text { equipment }\end{array}$} & \multirow{2}{*}{ 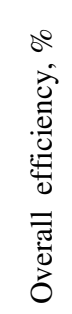 } & \multicolumn{5}{|c|}{ Efficiency of capture, $\%$} \\
\hline & & $\begin{array}{l}<5 \\
\mu \mathrm{m}\end{array}$ & $\begin{array}{c}5-10 \\
\mu \mathrm{m}\end{array}$ & $\begin{array}{c}10-20 \\
\mu \mathrm{m}\end{array}$ & $\begin{array}{c}20-40 \\
\mu \mathrm{m}\end{array}$ & $\begin{array}{c}>40 \\
\mu \mathrm{m}\end{array}$ \\
\hline $\begin{array}{l}\text { Dust } \\
\text { settling } \\
\text { chamber }\end{array}$ & 58.6 & 7.5 & 22 & 43 & 80 & 90 \\
\hline Cyclone & 65.3 & 12 & 33 & 57 & 82 & 91 \\
\hline $\begin{array}{l}\text { Cyclone } \\
\text { with } \\
\text { elongated } \\
\text { cone }\end{array}$ & 84.2 & 40 & 79 & 92 & 95 & 97 \\
\hline $\begin{array}{l}\text { Electrofil- } \\
\text { ter }\end{array}$ & 97.0 & 72 & 94.5 & 97 & 99.5 & 100 \\
\hline $\begin{array}{l}\text { Hollow } \\
\text { scrubber }\end{array}$ & 98.5 & 90 & 96 & 98 & 100 & 100 \\
\hline $\begin{array}{l}\text { Venturi } \\
\text { scrubber }\end{array}$ & 99.5 & 99 & 99.5 & 100 & 100 & 100 \\
\hline Hose filter & 99.7 & 99.5 & 100 & 100 & 100 & 100 \\
\hline $\begin{array}{l}\text { Vortex } \\
\text { scrubber }\end{array}$ & 99.8 & 99.9 & 100 & 100 & 100 & 100 \\
\hline
\end{tabular}

In the vortex dust collector there is no wear of the internal walls of the apparatus, which is due to the peculiarities of its air regime. The device is more compact than other designs of dust collectors. The use of hollow vortex devices in this method of cleaning gas emissions will 


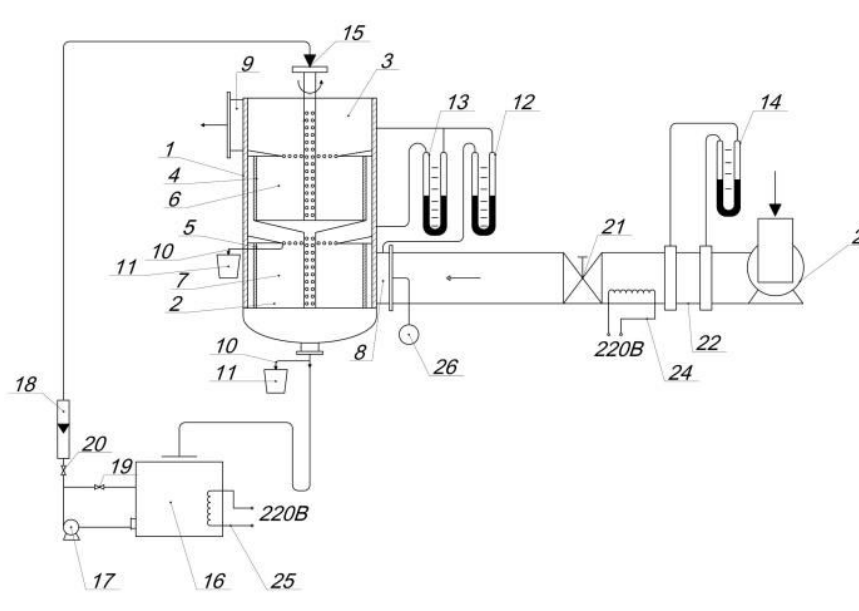

Figure 2 - The apparatus for studying the work parameters of a vortex apparatus: 1 - vortex device; 2 - the working section, 3 - the droplet separator, 4, 5 - the tangential swirler; 6,7 - the contact sections; 8 - gas inlet; 9 - gas outlet;

10 - the sampling pipe; 11 - measuring cup; $12-14$ - manometers; 15 - fluid inlet; 16 - tank; 17 - centrifugal pump;

18 - flowmeter; 19,20 - valves; 21 - gate valve; 22 - diaphragm; 23 - gas blowers; 24,25 - heating element; 26 - psychrometer

reduce the consumption of liquid for wet cleaning. By adjusting the speed of the gas at the inlet to the apparatus, it is possible to ensure optimum operation in the vortex apparatus.

The design of equipment for the study of the parameters of the vortex apparatus is shown in Fig. 2.The flow of liquid enters the apparatus through the gas-phase connection. From the holes in the sprinkler, the liquid is sprayed into the working area of the apparatus. The swirling flow of gas interacts intensely with the liquid. Rotating together with the gas-liquid flow, dust particles move to the surface of liquid droplets. Under the action of the centrifugal force, the liquid precipitates on the wall of the apparatus and flows down along it in the form of a film. This creates an additional contact zone of the gas and liquid phases. The gas, passing through the droplet layer, is cleaned of solid impurities, after which it is removed from the apparatus through the upper nozzle. The used liquid is removed through the lower nozzle.

The main advantages of this device are high throughput in the gas phase and low hydraulic resistance. These factors necessitate the joint use of already installed cyclones at the enterprises simultaneously with vortex devices for gas purification from cleaning matter in soda plants. In order to pre-clean the large particles of soda, the gas is supplied to the apparatus for trapping large particles, for example, a cyclone. After that, the gas enters the vortex apparatus for wet cleaning from small dust particles. The liquid in the vortex device comes from the condenser. The spent liquid from the dust trap is taken to the evaporation apparatus, where the concentration of the solution is taken, which is then taken to the crystallizer to separate the soda crystals. Water vapor is then fed to the condenser, and then returns to the hollow vortex device (Fig. 3).

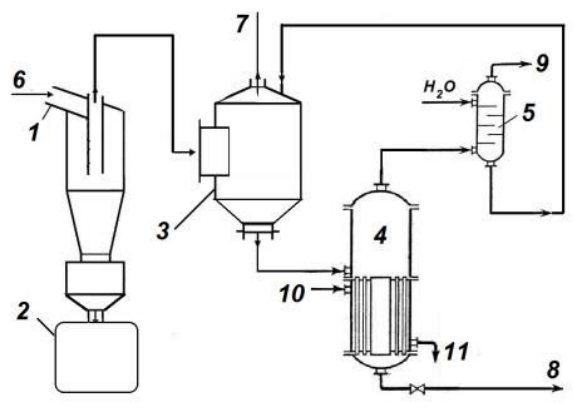

Figure 3 - Scheme of cleaning the air flow from the soda dust: 1 - cyclone; 2 - dust collector; 3 - vortex apparatus; 4 - evaporator; 5 - condenser; 6 - input of a dusty gas; 7 - cleaned gas outlet; 8 - outlet of the evaporated solution; 9 - air outlet to the atmosphere; 10 - input of heating steam; 11 - outlet of condensate of heating steam

The proposed gas purification method can also be used in other industries to purge from soluble dust crystals. The use of hollow vortex sludge devices in this method will reduce the consumption of liquid for cleaning from dust. Also, adding a small amount of liquid to the swirler by spraying it, makes it possible to lower the hydraulic resistance of the apparatus.

Thus, it is advisable to use the proposed apparatus in this technological scheme. The efficiency of deposition of submicron particles in a device with intensive phase interaction can exceed $95 \%$.

\section{Conclusions}

The use of the modernized two-stage purification scheme allows efficient air purification from dust of suspended solids. The use of hollow vortex devices in this method will eliminate the problem of clogging equipment and communications with sediments. In addition, the main advantages of vortex devices is the simplicity of manufacturing, installation and maintenance, small overall dimensions, large phase contact surface, high efficiency of trapping fine particles and high gas phase productivity. Using a recycled liquid will result in a lower power consumption of the installation. This makes the installation promising for practical use to improve economic and environmental performance.

For the soda industry, the necessity of introducing fundamentally new compact and highly efficient absorbers, capable of working at high $L / Q$ ratio, has been long overdue, providing not only the intensification of gas absorption processes but also the solution of a number of environmental problems of soda production.

Thus, the main result of the work is updating of the technology of ammonia and dust emissions, development a new construction of equipment, which contributes significantly to the improvement of soda production as an important sub-sector of the chemical industry. 


\section{References}

1. Issledovaniye problem razrabotki, vnedreniya i razvitiya tekhnologiy kompleksnoy zashchity cheloveka pri chrezvychaynykh situatsiyakh. FGU VNII GOChS, Moscow, 2007, pp. 166 [in Russian].

2. Tkach, G. A., Shaporev, V. P., \& Titov, V. M. (1998). Proizvodstvo sody po malootkhodnoy tekhnologii. KHGPU, Kharkiv [in Russian].

3. Proceedings of the International Conference "World soda ash". Riviera, 2007.

4. Sabitov, S. S., Savel'yev, P. I., et al. (1981). Vikhrevyye massoobmennyye apparaty. Obshcheotraslevyye voprosy razvitiya khimicheskoy promyshlennosti, Moscow, NIITEKhIM, Issue 3 [in Russian].

5. Nikolayev, L. N., Ovchinnikov, A. A., \& Nikolayev P. A. (1992). Vysokoeffektivnyye vikhrevyye apparaty dlya kompleksnoy ochistki bol'shikh obyomov promyshlennykh gazovykh vybrosov. Khimicheskaya promyshlennost', No. 9, pp.36-38 [in Russian].

6. Moiseev, V. F., Manoylo, E. V., \& Hrubnik A. O. (2015). Intensyfikatsiya promyvacha hazu kolon u vyrobnytstvi kal'tsynovanoyi sody. Tekhnologicheskiy audit i rezervy proizvodstva, Kharkiv: Tekhnolohichnyy Tsentr, No. 6/4 (26) [in Ukrainian].

7. Moiseev, V. F., Manoylo, E. V., \& Hrubnik A. O. (2016). The decrease in technogenic load on the environment during the process of absorption of ammonia in soda industry. Journal of Engineering Sciences, Vol. 3, Issue 2, pp. G1-G7.

8. Krasheninnikov, S. A. (1985). Tekhnologiya kal'tsinirovannoy sody i ochishchennogo bikarbonata natriya. Vysshaya shkola, Moscow [in Russian]. 